\title{
Functional analysis of the thymic microenvironment using recombinant single chain antibodies
}

\author{
D.B. Palmer, A. Solomou and M.A. Ritter \\ Department of Immunology, Division of Medicine, \\ Imperial College School of Medicine, Hammersmith \\ Hospital, London, W12 ONN, UK
}

Thymic stromal cells play a crucial role in T lymphocyte development, although the precise molecular interactions that are involved are largely unknown. To investigate these processes, we used a phage display library expressing recombinant single chain antibodies (scFv) [1] and have selected reagents with specificity for molecules expressed on the surface of cortical epithelial cells using either thymic stromal cells [2] or purified microenvironmental molecules as selection substrate. The majority of the $\mathrm{scFv}$ recognise evolutionarily conserved epitopes present in the thymus of a wide range of species including human, mouse, rat, pig and chicken. The molecules detected have been analysed by Western blotting; they include the gp200MR6 antigen [3], previously identified only in the human thymus, while others are novel thymic molecules. Some of these $\mathrm{scFv}$ influence $\mathrm{T}$ cell development in fetal thymic organ culture, indicating that their target molecules play an important role in the interaction between developing thymocytes and the epithelial microenvironment. Others have a direct differentiative effect on epithelium, suggesting that their ligand may play a role in thymocyte-epithelial crosstalk. Our data highlight the power of phage display technology for the selection of specific reagents, for detection of conserved epitopes/molecules on thymic epithelium and for the production of recombinant $\mathrm{scFv}$ whose small size enhances tissue penetration and therefore their efficacy in functional analysis.

\section{References}

[1] A. Nissim, H.R. Hoogenboom, I.M. Tomlinson, G. Flynn, C. Midgley, D. Lane and G. Winter, EMBO J. 13 (1994), 692.

[2] D.B. Palmer, A.J.T. George and M.A. Ritter, Immunology 91 (1997), 473.

[3] P.F. McKay, N. Imami, M. Johns, D.A. Taylor-Fishwick, L.M. Sedibane, N.F. Totty, N.F. Hsauan, D.B. Palmer, A.J.T. George, B.M.J. Foxwell and M.A. Ritter, Eur. J. Immunol. 28 (1998), 4071. 


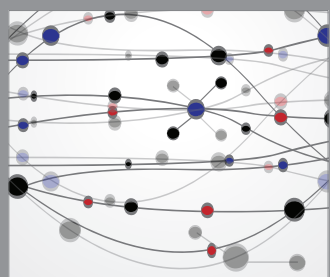

The Scientific World Journal
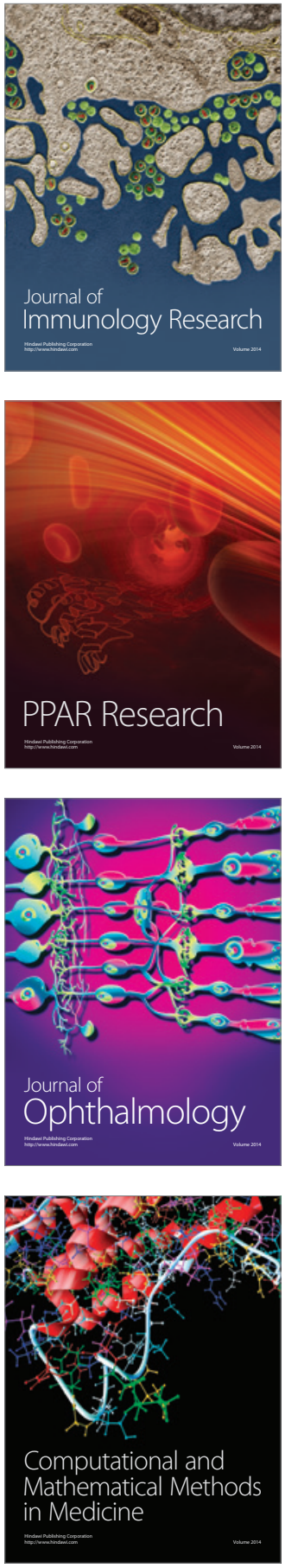

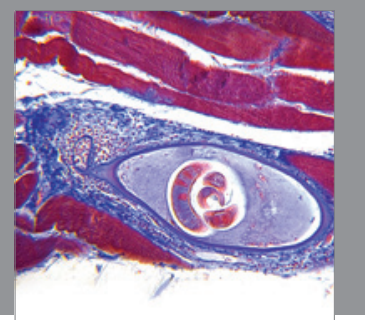

Gastroenterology

Research and Practice
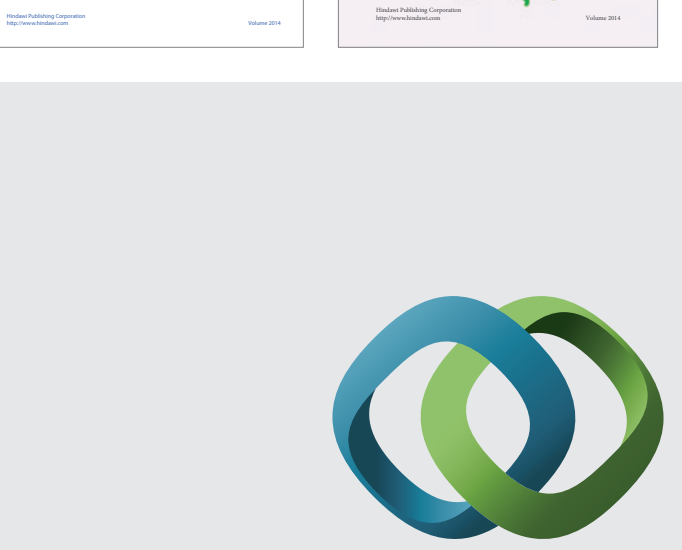

\section{Hindawi}

Submit your manuscripts at

http://www.hindawi.com
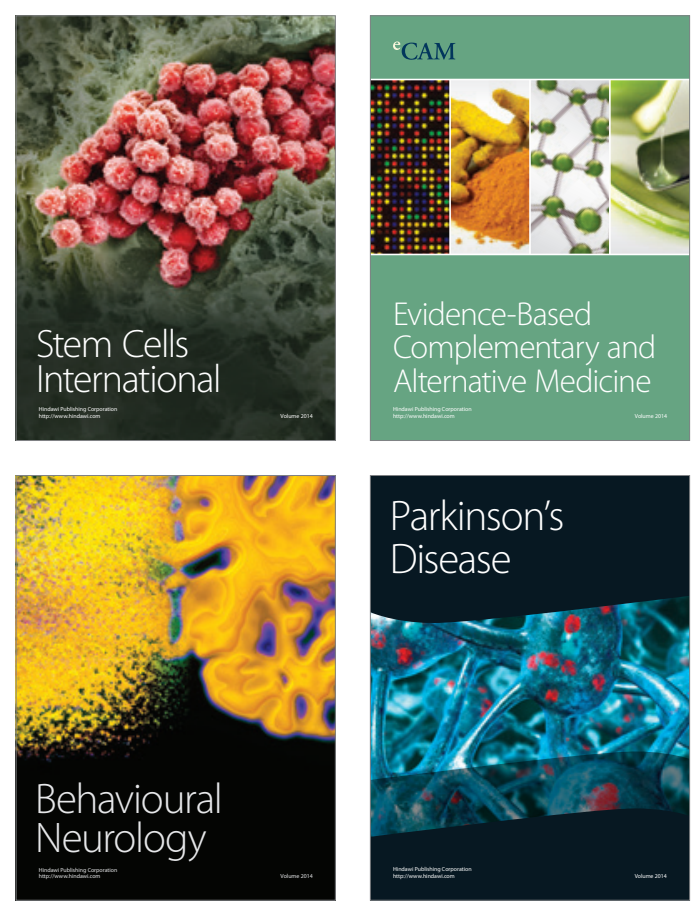

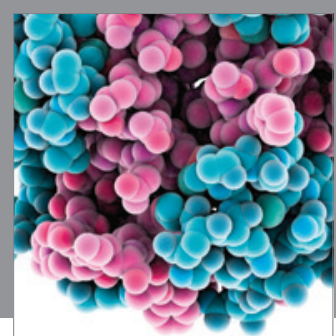

Journal of
Diabetes Research

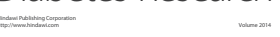

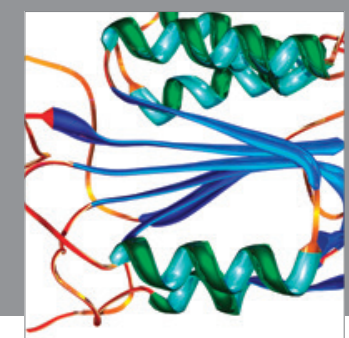

Disease Markers
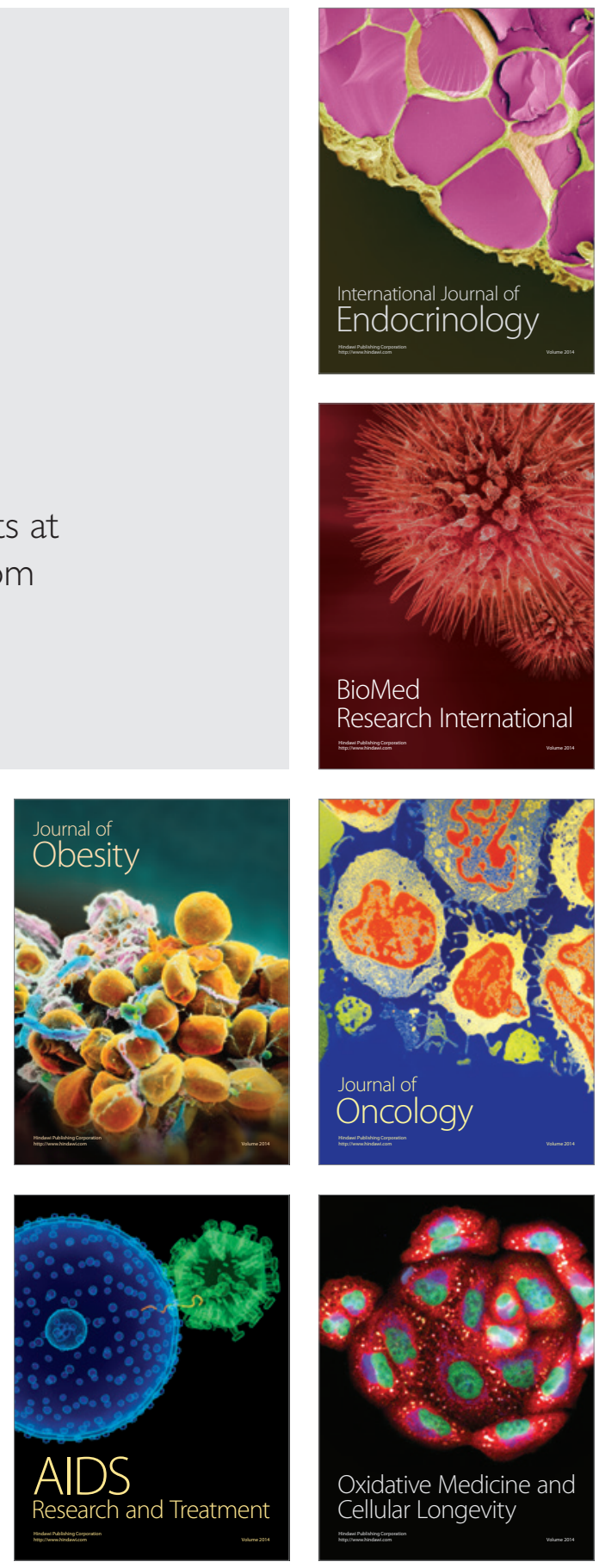